\title{
The Piling Installation Vibration Damage Behaviour on Drainage at Construction Site
}

\author{
Adhilla Ainun Musir ${ }^{1, *}$, Nurulzatushima Abdul Karim ${ }^{1}$, Mohd Samsudin Abdul Hamid, \\ Emir Shahreman Dilah ${ }^{1}$, Daliah Hasan ${ }^{1}$, Mohd Farid Ahmad Majid ${ }^{2}$ \\ ${ }^{1}$ School of Civil Engineering, College of Engineering, Universiti Teknologi MARA, Cawangan Pulau Pinang, \\ Kampus Permatang Pauh, 13500 Pulau Pinang, Malaysia \\ ${ }^{2}$ Farid Ahmad Consulting Engineers Sdn. Bhd., No. 8-2 (2 ${ }^{\text {nd }}$ Floor), Jalan Puteri 2A/1, Bandar Puteri Bangi, 4300 Kajang, \\ Selangor Darul Ehsan, Malaysia
}

Received February 3, 2021; Revised July 26, 2021; Accepted August 9, 2021

\section{Cite This Paper in the following Citation Styles}

(a): [1] Adhilla Ainun Musir, Nurulzatushima Abdul Karim, Mohd Samsudin Abdul Hamid, Emir Shahreman Dilah, Daliah Hasan, Mohd Farid Ahmad Majid, "The Piling Installation Vibration Damage Behaviour on Drainage at Construction Site," Civil Engineering and Architecture, Vol. 9, No. 6, pp. 2011-2017, 2021. DOI: 10.13189/cea.2021.090629.

(b): Adhilla Ainun Musir, Nurulzatushima Abdul Karim, Mohd Samsudin Abdul Hamid, Emir Shahreman Dilah, Daliah Hasan, Mohd Farid Ahmad Majid (2021). The Piling Installation Vibration Damage Behaviour on Drainage at Construction Site. Civil Engineering and Architecture, 9(6), 2011-2017. DOI: 10.13189/cea.2021.090629.

Copyright $\mathrm{C} 2021$ by authors, all rights reserved. Authors agree that this article remains permanently open access under the terms of the Creative Commons Attribution License 4.0 International License

\begin{abstract}
Nowadays, there are a lot of ongoing construction projects at nearby existing building and residential area. Each construction will have many effects such as environmental effect and damage effect on the existing infrastructure and building. The effects of construction activities include piling work to existing infrastructure or building produce settlements and cracks. This effect is usually caused by vibration effect from construction work. This study represents a research on the effect of vibration during piling installation that is generated by hydraulic piling machine for drainage located at construction site as damage object. All the data were recorded by Labview Signal Express Software and analysed by Microsoft excel. The result from the analysis of the relationship between the vibration with the distance showed that the vibration decreased when the distance increased. Other than that, it showed that all the vibration values were lower that the vibration limit.
\end{abstract}

Keywords Piling Installation, Drainage Structure, Vibration Effect, Vibration Limit

\section{Introduction}

Construction industry is one of the sectors that contribute to the development of a country. Deckner et al. (2015) approved that a lot of houses and infrastructure were constructed close to the existing structure and on land under poor ground condition.

The future development will give many benefits to citizens, but each construction will have many effects such as environmental effect and damage effect on the existing infrastructure and building (Massarsch, 2004). The environmental effects are air pollution, noise pollution and water pollution. The impact of the environment is that it disturbs inhabitants under unfavourable condition (Massarsch, 2004). The other effect of construction is concerned with the existing infrastructure or building like settlement and crack. This effect is usually caused by vibration effect from construction work (Musir \& Ghani, 2013; Lewis \& Davie, 1993). One of the impacts of the construction is vibration impact. According to Massarsch (2004), the construction activities generate the vibration during the driving of pile/sheet pile.

Pulau Pinang is one of the states in Malaysia that have rapid development. The amenities such as roads, housing and schools are developed by Pulau Pinang government, and it is expected that there will be new construction in the future. The future development will give many benefits to the citizens, but each construction produces 
many effects such as environmental effect and damage effect to the existing infrastructure and building (Massarsch, 2004). Other effects of construction include the effect on the existing infrastructure or building like settlement and crack. This effect is usually caused by vibration effect from construction work (Musir \& Ghani, 2013; Lewis \& Davie, 1993).

This study helps in avoiding negative impact on the surrounding. The study of Deckner et al. (2015) approved that the vibration can have a negative impact on the surrounding. It is also approved that vibration leads to damaged structure, disturbed occupants, and suspension of the construction work. This study is also used to avoid from fraudulent claims and for regulatory compliance to maintain the public relationship (Harrison, 2009). If negative impact occurs, it may unnecessarily cause conservative estimations and increase cost, limit the choice at construction method and delay the project. This study is developed to analyze the relationship of the vibration with distance between the pile point and the affected infrastructure.

Therefore, the aim of this study is to monitor the vibration effect on the drainage system during pile installation by analysing the relationship of the vibration due to the distance between poling point and the affected infrastructure.

\section{Literature Review}

\subsection{Vibration Transfer during Driven Pile}

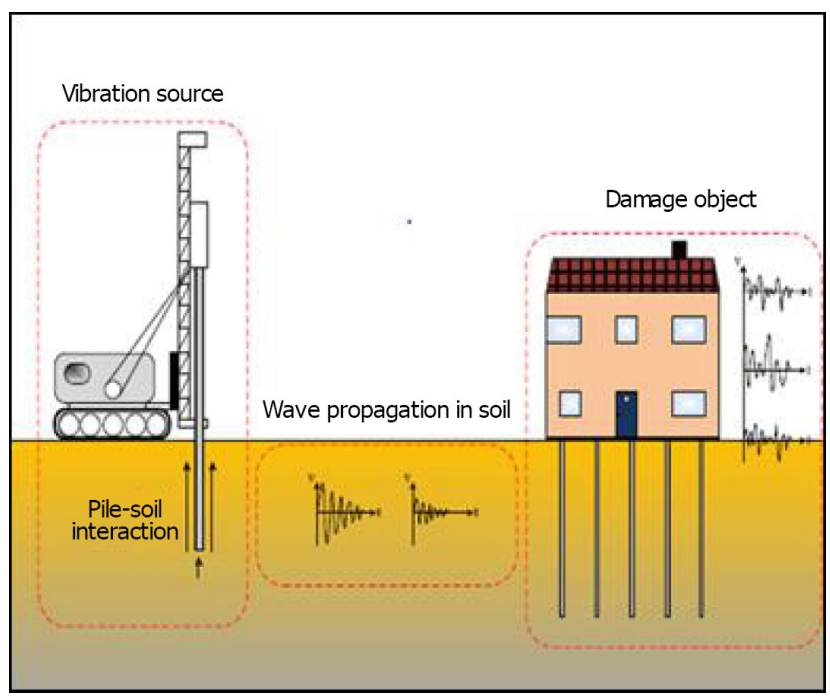

Figure 1. Schematic illustration of the vibration transfer during pile driving (Deckner et al. 2012)

To estimate the impact of pile/sheet pile driving, it is necessary to consider the entire vibration transfer process from the source to the defective object. This process is divided into three main parts: source of vibration, spread of ground waves and damage objects (Figure 1). Vibration is generated by driving the equipment and delivering it via a pile cap and directly into the pile. There is an interaction between the ground and the pile shaft and the pile toe, leading to the vibration delivered to the ground. From that vibration, it spreads through the ground and eventually interacts with possible damage objects. Therefore, farther distances between the damage object with the sources of the vibration is reduced by the vibration that the damage object receives (Deckner et al., 2012).

\subsection{Risk of Building Damage}

When designing a project where a driven pile or sheet piles is used, design engineers should identify potentially vulnerable structures and installations around the project site and propose ground vibration values. As part of this task, risks should be assessed against vibration damage to the structure and installation of vibrations - the vulnerability or environmental aspects affecting the occupants of the building. Since the prediction of building damage can be complicated, theoretical method has low reliability.

However, it is possible to assess the possibility of building damage based on statistical observation. This approach is used in codes and standards but is limited to the specific circumstances in the region where observations are made. Therefore, local building standards should be used with caution in other areas, where piling, geological conditions, and building standards may differ (Massarsch \& Fellenius, 2008).

\subsection{Mechanism of Damage}

The potential damage mechanism of the building must be clearly understood and assessed individually. Damage to construction work can be caused by different mechanisms. Many problems related to building damage are often associated with vibration but are actually caused by one of the other mechanisms. Each category of damage observed hereafter can, of course, occur concurrently (Massarsch, 2004). Figure 2 shows the damage category.

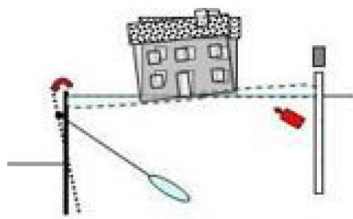

Category I. Static displacements

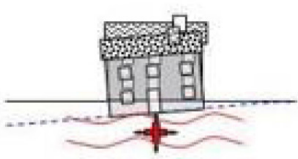

Category III. Cyclic loading

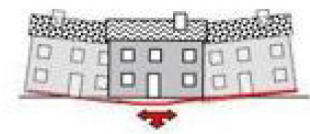

Category II. Ground distortion

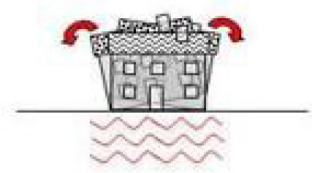

Category IV. Vibrations
Figure 2. Damage Category (Massarsch, 2004) 


\subsection{Vibration Source during Pile Driving}

For forecasts and analysis of ground vibrations during pile driving, it is important to note that vibration sources change during pile penetration into the ground. Conventional geotechnical investigations by using penetration tests are usually sufficient to identify possible critical layers for vibration emission.

Three general conditions of the pile assembly that can cause excessive ground vibrations are shown in Figure 3. Case A illustrates the pile driving to a fierce surface layer. Energy sources are at ground level and the vibrations will spread primarily in the form of surface waves. This case can be easily analyzed using a simple vibration dispersion method. Case B is typical for displaced haemorrhoids that are pushed into compact and compact solid deposits.

Most vibrational power will disappear along the pile shaft. At horizontal distances twice the pile penetration, the vertical polarized shear wave will turn into a gradual surface wave. In thick sand or in terms of barriers, vibrations can also be transmitted from pile bases, particularly in the form of compressive waves. Case $\mathrm{C}$ is typical for driving towards the final pile rejection. Also in this case, the vibrations will spread as body waves (especially compression waves) to the ground, and it is transformed into surface waves (Massarsch, 2004).

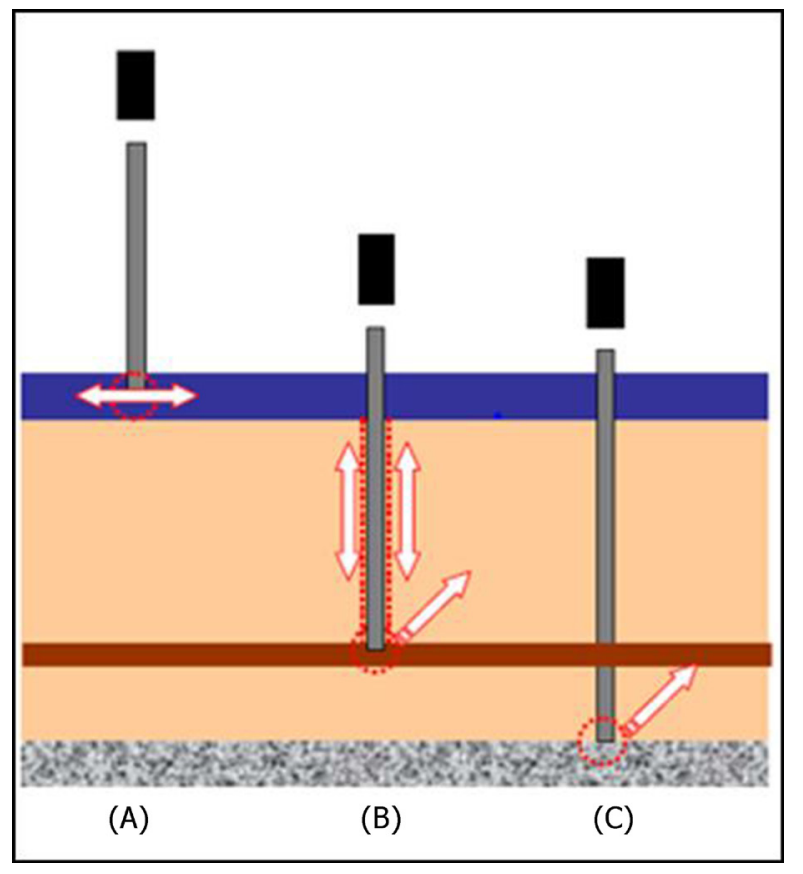

Figure 3. Ground vibrations Typical cases during pile installation (Massarsch, 2004)

\subsection{Potential Damages to Buildings}

The vibration standard is in the unit velocity of the particle with frequency dependency. These standards are designed to protect drywall and plaster from cosmetic cracking; structural damage requires vibration two to five times higher than the standard used.

\subsubsection{Standard-Transient Vibrations (Impact Hammer)}

Here is a list of acceptable vibration limits for the temporary vibration level for pile driving and other construction activities developed by the US Mines Bureau:

- PPV limit to $19.05 \mathrm{~mm} / \mathrm{sec}(0.75 \mathrm{in} / \mathrm{sec})$ for low frequency vibration $(<12$ Hertz)

- PPV $25.5 \mathrm{~mm} / \mathrm{sec}(1.0 \mathrm{inch} / \mathrm{sec})$ for a frequency of $20 \mathrm{~Hz}$ and PPV of $50.8 \mathrm{~mm} / \mathrm{sec}(2.0$ inch / sec) for higher frequency vibration.

\subsubsection{Standard Vibration-Steady State (Vibratory Hammer)}

Here is a summary of information on vibration limits for steady state vibration levels to guide piling and other construction activities (Harrison, 2009):

- The vibration from a steady-state source is usually limited to PPV of $12.7 \mathrm{~mm} / \mathrm{sec}(0.5 \mathrm{inch} / \mathrm{sec})$ or less.

- Greater potential for resonance due to cycle / duration cycles

- Fatigue breaks anxiety because of the number of cycles

- Low frequency vibrations usually occur when the ramping goes up and down at the start and stops (Vibrating hammer, for example)

- The "walking" object on the shelf is more attentive to the steady-state vibration, even further below the standard structure of the safe.

\section{Methodology}

This research aims to measure the vibration rates received by the drainage to predict the vibration that may give damage impart to the drainage. From the data collected, the data need to be compared with the literature review collected from other researchers.

Three pile points with different distance were selected to analyze vibration with different distance. The data need to be recorded into LabView SignalExpress Software before the pile passes through the mark (5ft. mark) until the mark passes away. The data recorded needs to be repeated until the last mark on the pile. This test will be repeated for another pile point.

The data that need to be collected at construction site to complete this research are vibration data, size of pile, length of pile, and distance between the pile's point with the affected drainage as stated in Figure 4. 


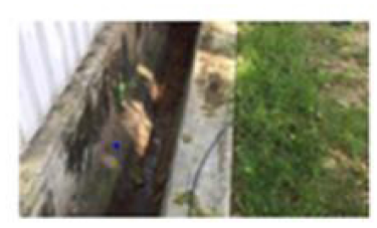

Choose the suitable area to set up the instrument. The area must consider the place to set up accelerometer and the laptop.
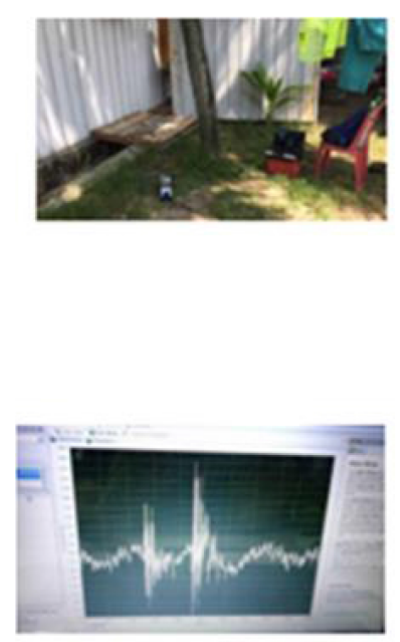

Measure the distance between the pile point and the accelerometer for each pile that use in this study!

\section{Result}

The vibration that generates during the piling installation was measured by using accelerometers LabView Signal Express soft installed in construction site during the running of piling installation work. The distance between the points of pile and the accelerometer was recorded.

The accelerometer and LabView Signal Express software are the instruments used to measure the vibration that is generated during piling installation at the construction site of Bandar Sunway Seberang Jaya. The result was recorded using LabView Signal Express Software and the recorded data were interpreted using Microsoft excel while the value of the vibration was chosen with the highest value for each point.

\subsection{Distance between Pile and Accelerometer}

After the point of the piles was identified, the measuring tape was used to measure the distance between the piles point with the accelerometer installed location. The distance for each pile point and each accelerometer was recorded in Table 1. Figure 1 shows the condition of piles and the condition of the accelerometer.

Table 1. Distance between pile and accelerometer

\begin{tabular}{|c|c|c|}
\hline \multirow{2}{*}{$1^{\text {st }}$ PILE } & $1^{\text {st }}$ accelerometer & $33.62 \mathrm{~m}$ \\
& $2^{\text {nd }}$ accelerometer & $32.02 \mathrm{~m}$ \\
\hline \multirow{2}{*}{$2^{\text {nd }}$ PILE } & $1^{\text {st }}$ accelerometer & $36.75 \mathrm{~m}$ \\
& $2^{\text {nd }}$ accelerometer & $35.15 \mathrm{~m}$ \\
\hline \multirow{2}{*}{$3^{\text {rd }}$ PILE } & $1^{\text {st }}$ accelerometer & $28.40 \mathrm{~m}$ \\
& $2^{\text {nd }}$ accelerometer & $26.80 \mathrm{~m}$ \\
\hline
\end{tabular}

Figure 4. Field test flowchart

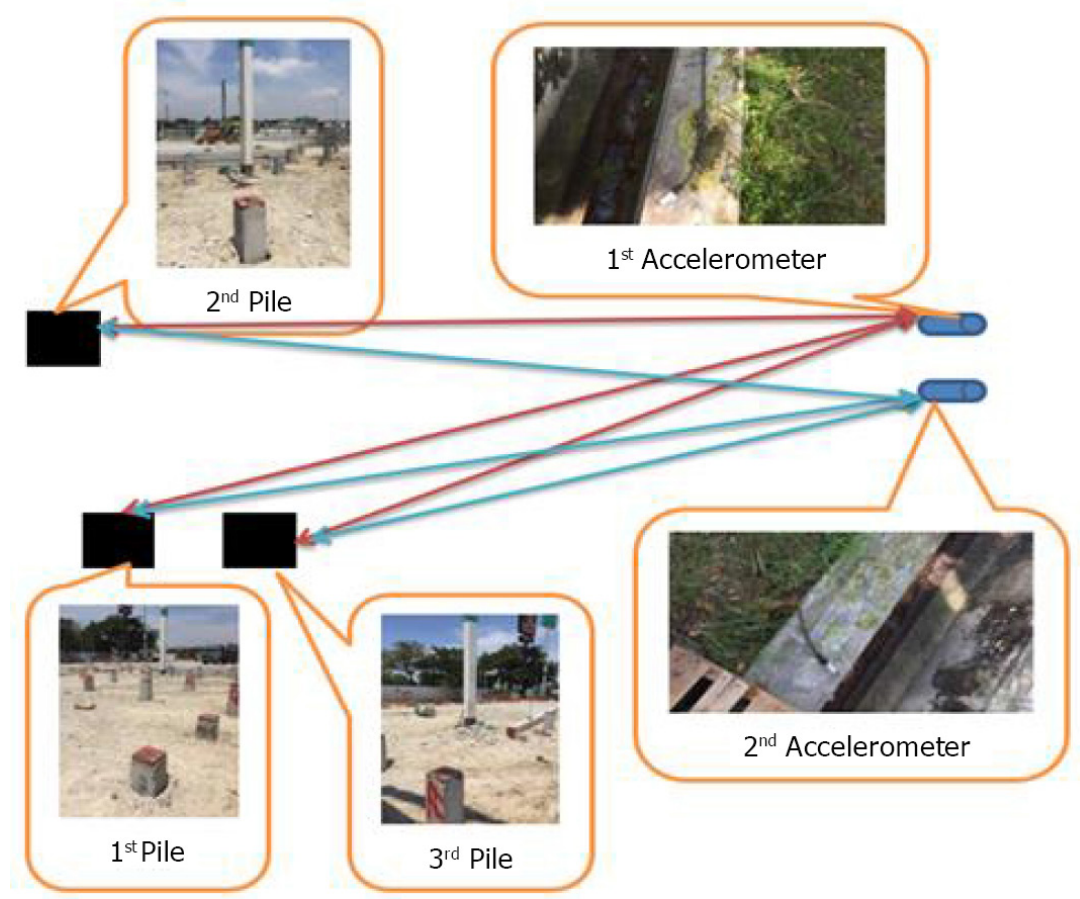

Figure 5. Condition of piles and the accelerometer 
The vibration data recorded by Labview Signal Express Software was interpreted using Microsoft Excel which identified the value of the vibration in number form to get the accurate value. Besides that, Microsoft excel facilitated the election of the maximum value among the total value of data collection. Usually, the total value of data collection is around $20000-40000$ data for each time the data are recorded. The data were recorded for each $5 \mathrm{ft}$ depth for each pile. The max values were chosen for each recorded data as depicted in Table 2, Table 3, and Table 4.

Table 2. Max value of vibration for 1 st pile

\begin{tabular}{|c|c|c|}
\hline No & $1^{\text {st }}$ accelerometer & $2^{\text {nd }}$ accelerometer \\
\hline 1 & 0.002324 & 0.002341231 \\
\hline 2 & 0.001925 & 0.002173382 \\
\hline 3 & 0.00268 & 0.002964435 \\
\hline 4 & 0.001804 & 0.001857202 \\
\hline 5 & 0.002001 & 0.00202375 \\
\hline 6 & 0.002011 & 0.002021148 \\
\hline 7 & 0.001773 & 0.001954789 \\
\hline 8 & 0.002008 & 0.002511682 \\
\hline 9 & 0.002006 & 0.002690593 \\
\hline 10 & 0.002014 & 0.002433013 \\
\hline 11 & 0.002332 & 0.002491514 \\
\hline 12 & 0.002147 & 0.002409596 \\
\hline 13 & 0.002047 & 0.002248199 \\
\hline 14 & 0.002255 & 0.002744581 \\
\hline 15 & 0.002346 & 0.002683438 \\
\hline 16 & 0.00218 & 0.002483057 \\
\hline
\end{tabular}

Table 3. Max value of vibration for $2^{\text {nd }}$ pile

\begin{tabular}{|c|c|c|}
\hline No & $1^{\text {st }}$ accelerometer & $2^{\text {nd }}$ accelerometer \\
\hline 1 & 0.001903393 & 0.002021275 \\
\hline 2 & 0.002083603 & 0.002289913 \\
\hline 3 & 0.002447973 & 0.002511682 \\
\hline 4 & 0.001493756 & 0.001839147 \\
\hline 5 & 0.001982764 & 0.002235838 \\
\hline 6 & 0.001926959 & 0.002152564 \\
\hline 7 & 0.002047821 & 0.002399783 \\
\hline 8 & 0.001911851 & 0.002172732 \\
\hline 9 & 0.002047821 & 0.002170129 \\
\hline 10 & 0.002030906 & 0.002190948 \\
\hline 11 & 0.002013341 & 0.002267716 \\
\hline 12 & 0.002099217 & 0.002107024 \\
\hline 13 & 0.002030256 & 0.002282029 \\
\hline 14 & 0.002011389 & 0.002314557 \\
\hline 15 & 0.001991221 & 0.00241415 \\
\hline 16 & 0.002060833 & 0.002179888 \\
\hline
\end{tabular}

Table 4. Max value of vibration for $3^{\text {rd }}$ pile

\begin{tabular}{|c|c|c|}
\hline No & $1^{\text {st }}$ accelerometer & $2^{\text {nd }}$ accelerometer \\
\hline 1 & 0.001709056 & 0.001431963 \\
\hline 2 & 0.003420404 & 0.004069558 \\
\hline 3 & 0.002496107 & 0.002546842 \\
\hline 4 & 0.00247204 & 0.002542289 \\
\hline 5 & 0.002341299 & 0.002398539 \\
\hline 6 & 0.001963384 & 0.002021925 \\
\hline 7 & 0.001768898 & 0.001876223 \\
\hline 8 & 0.002052497 & 0.002420654 \\
\hline 9 & 0.001994606 & 0.002081767 \\
\hline 10 & 0.002349755 & 0.00240089 \\
\hline 11 & 0.002163724 & 0.002431712 \\
\hline 12 & 0.002462904 & 0.002652867 \\
\hline 13 & 0.002787961 & 0.002907845 \\
\hline 14 & 0.002848654 & 0.003180386 \\
\hline 15 & 0.002133153 & 0.00224373 \\
\hline 16 & 0.002862964 & 0.003333893 \\
\hline
\end{tabular}

\subsection{Relationship between the Vibration and the Distance}

Based on the results in Table 2, Table 3 and Table 4, the maximum value of the vibration was chosen for each pile point. From the result, there were three maximum values of the vibration with different distance for each accelerometer. The maximum value of vibration with the distance was recorded in Table 5.

From Table 5, a graph was generated to know the relationship between the vibrations and the distance. Figure 6 shows that the $y$-axis represents value vibration in unit G-force(g) while the $\mathrm{x}$-axis represents distance in unit meter(m).

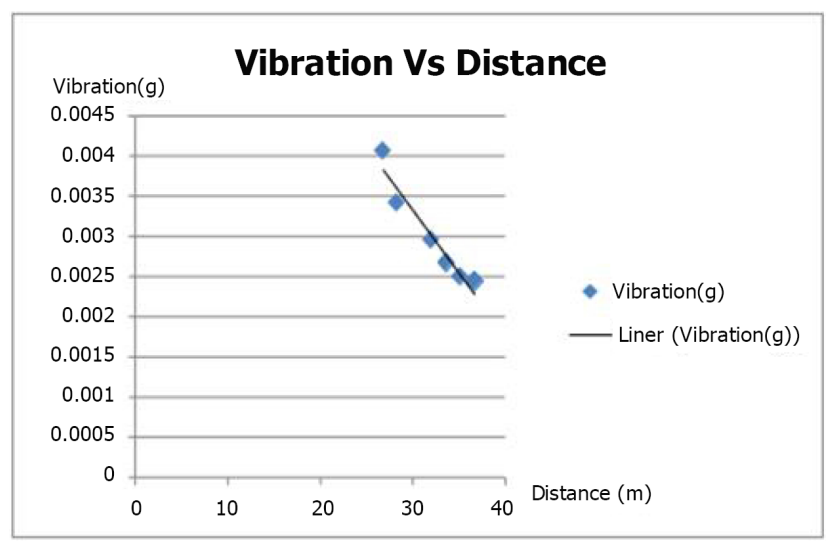

Figure 6. Relationship between the vibration and the distance

Table 5. The maximum value of vibration with the distance

\begin{tabular}{|c|c|c|c|c|c|c|}
\hline & \multicolumn{3}{|c|}{ Accelerometer 1 } & \multicolumn{3}{c|}{ Accelerometer 2 } \\
\hline & $1^{\text {st }}$ Pile & $2^{\text {nd }}$ Pile & $3^{\text {rd }}$ Pile & $1^{\text {st }}$ Pile & $2^{\text {nd }}$ Pile & $3^{\text {rd }}$ Pile \\
\hline Vibration $(\mathrm{g})$ & 0.00267953 & 0.002447973 & 0.003420404 & 0.002964435 & 0.002511682 & 0.004069558 \\
\hline Distance $(\mathrm{m})$ & 33.62 & 36.75 & 28.40 & 32.02 & 35.15 & 26.80 \\
\hline
\end{tabular}


Figure 6 shows that the value of vibration decreased due to the increase of the distance. The result proved the statement by Deckner, Viking and Hintze (2012) which stated that the farther distances between the damage object with the sources of the vibration is reduced by the vibration that the damage object receives.

The data of the vibration recorded at the construction site is in unit G-forces $(\mathrm{g})$. To compare the result recorded at the construction site, the value of the vibration needs to be converted into unit inch per seconds(in/s) because the value of the vibration must be in the same unit with the unit of vibration data gotten from literature review. The values that were converted are recorded in Table 6.

From Table 6, a bar chart was created to show the value of vibration collected in construction site and the vibration limit as stated in literature review. Jackson and Hammons (2007) showed that 2 in / sec is the vibration limit criterion. This study used that value as a vibration limit for reference of this study.

Figure 7 shows that the vibration value collected in the construction site was lower than the vibration limit. Briefly, the vibration that is generated during piling installation will not affect the infrastructure. Therefore, the construction is allowed by government authority because the vibration will not cause any damage to the existing infrastructure.

\section{Conclusion}

This study has attempted to get a better understanding of the effect of vibration on building or infrastructure due to piling installation. During field test, the data were collected to complete this study. The data were supported by previous study of other researchers. By analyzing the relationship between the vibration with the distance, it shows that the vibration decreases when the distance is increased. Besides, from the analysis of the vibration value that was compared with the vibration limit collected in literature review, it is shown that all the vibration values were lower that the vibration limit. Therefore, the drainage as a damage object in this study is not affected.

Depending on the result, it could be used as a reference to make a study about vibration on piling installation on another construction site in future project. Hence, the authority should be more sensitive on the terms of use of machinery such as piling installation machine. For urban area, hydraulic hammer piling machine should not be used because the hydraulic hammer piling machine will generate more vibration that can have effect on other building.

Table 6. The vibration value in unit in/s

\begin{tabular}{|c|c|c|c|c|c|c|}
\hline & \multicolumn{3}{|c|}{ Accelerometer 1 } & \multicolumn{3}{c|}{ Accelerometer 2 } \\
\hline & $1^{\text {st }}$ Pile & $2^{\text {nd }}$ Pile & $3^{\text {rd }}$ Pile & $1^{\text {st }}$ Pile & $2^{\text {nd }}$ Pile & $3^{\text {rd }}$ Pile \\
\hline Vibration (g) & 0.00267953 & 0.002447973 & 0.003420404 & 0.002964435 & 0.002511682 & 0.004069558 \\
\hline Vibration (in/s) & 0.0233 & 0.0213 & 0.0297 & 0.0258 & 0.0218 & 0.0354 \\
\hline
\end{tabular}

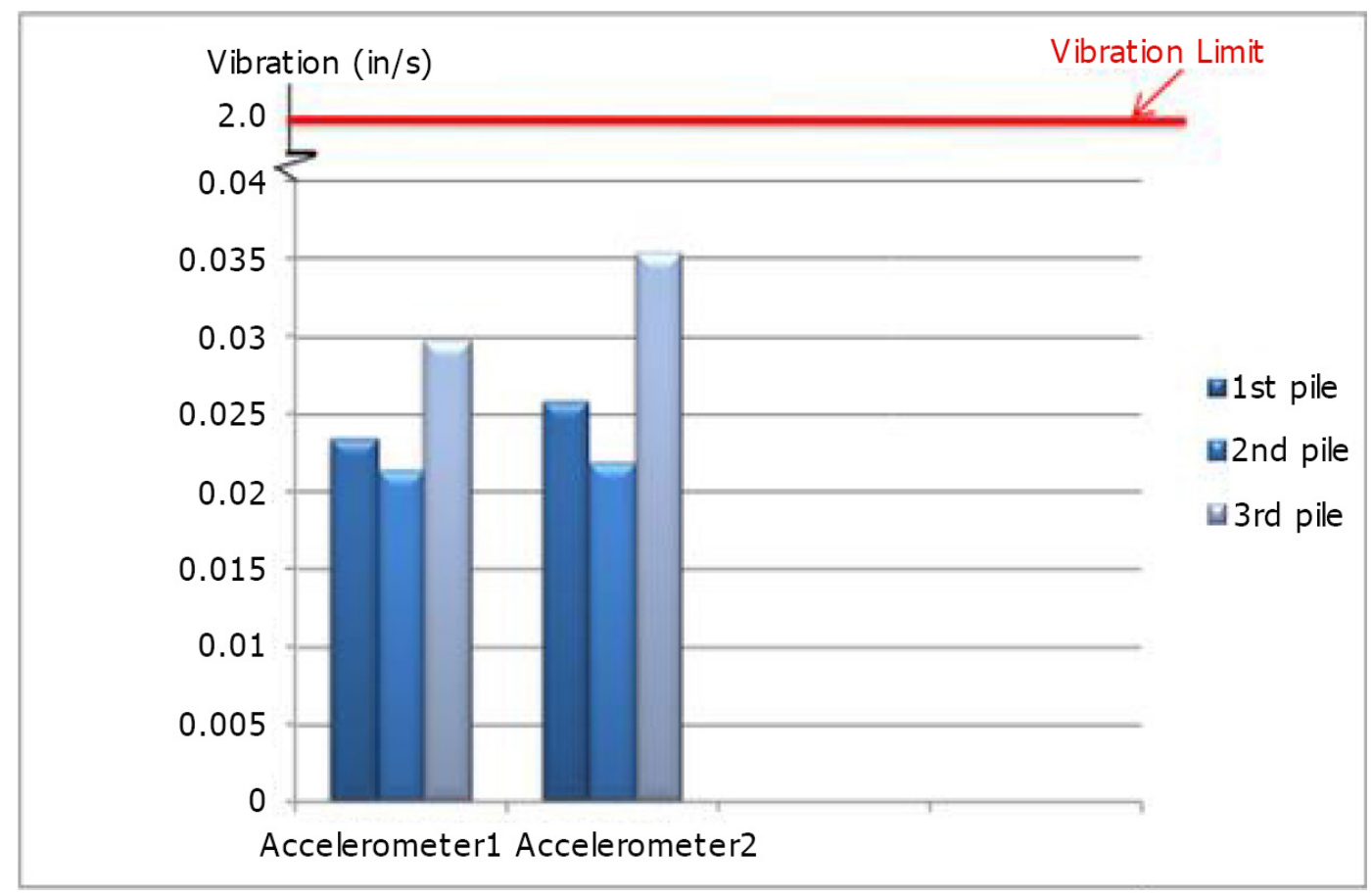

Figure 7. Comparison on the vibration value with the vibration limit 


\section{Acknowledgments}

The authors acknowledge Universiti Teknologi MARA Pulau Pinang for the financial support. The authors are grateful to Geotechnical laboratory technician for the help in completing this research.

\section{REFERENCES}

[1] A. A. Musir, A. N. A. Ghani. Pile Driving Effects on Nearby Building. Third International Conference on Geotechnique, Construction Materials and Environment, Nagoya, Japan, Nov. 13-15, 2013, ISBN: 978-4-9905958-2-1 C3051

[2] E.Barbin, A.Koleda, T.Nesterenko, S.Vtorushin. Three-axis MEMS Accelerometer for Structural Inspection. Journal of Physics: Conference Series 671 (2016) 012003.

[3] D.Harrison. Monitoring Pile Driving Vibrations - Problem Avoidance and Case Studies. Vice President and Principal, Seismic Surveys, Inc, 4375 Gibsonia Road, Suite 4, Gibsonia, Pennsylvania.

[4] M. R. Lewis, J. R. Davie. Vibrations Due to Pile Driving. International Conference on Case Histories in Geotechnical Engineering. 8.1993

[5] F. Deckner, K. Viking, S. Hintze. Ground Vibrations Due to Pile and Sheet Pile Driving - Prediction Model of Today. Proceedings of the 22nd European Young Geotechnical Engineers Conference, Gothenburg, Sweden, 26-29 August 2012.

[6] F. Deckner, K. Viking, S. Hintze. Vibration Transfer During Sheet Pile Driving - A Full-Scale Field Test. 6th International Conference on Earthquake Geotechnical Engineering, 4 November 2015, Christchurch, New Zealand.

[7] K.R.Massarsch. Vibration Caused by Piling Driving, The Magazine of the Deep Foundations Institute. 2004.

[8] J. Ayarkwa, A. Acheampong, J. K. Hackman, K. Agyekum. Environmental Impact of Construction Site Activities in Ghana. Africa Development and Resources Research Institute Journal, Ghana: Vol. 9, No. 9(2). 2014.
[9] N.M. Jackson, M.I. Hammons. Use of Nondestructive Techniques to Estimate the Allowable Vibratory Compaction Level During Construction. Research Report FL/DOT/SMO/07-BDB-11, State Materials Office, March 2007.

[10] K. R. Massarsch. Settlements and damage caused by construction-induced vibrations. Proceedings, Intern. Workshop Wave 2000, Bochum, Germany 13 - 15 December 2000, pp. $299-315$

[11] J.F. Wiss. Construction Vibrations: State-of-the-Art Journal of the Geotechnical Engineering Division, ASCE, Vol. 107, No. GT2, February 1981, pp. 167-181.

[12] K.R. Massarsch, B.B. Broms. Damage Criteria for Small Amplitude Ground Vibrations. Second International Conference on Recent Advances in Geotechnical Earthquake Engineering and Soil Dynamics, St. Louis, Missouri, March 11-15, 1991, Vol. 2, pp 1451-1459.

[13] R.D. Woods. Dynamic Effects of Pile Installations on Adjacent Structures. Synthesis of Highway practice 253, National Cooperative highway research program, Washington, D.C., 1997.

[14] K.M. Massarsch, B.H. Fellenius. Ground Vibrations Induced by Impact Pile Driving. Sixth International Conference on Case Histories in Geotechnical Engineering, August 12-16, Arlington VA, Virginia, 2008, 38 p.

[15] D.S. Kim, S. Drabkin, A. Rokhavarger, D. Laefer. Prediction of Low-Level Vibration Induced Settlement. Vertical and Horizontal Deformations of Foundations and Embankments, ASCE Geotechnical Special Publication No. 40, 1994, pp. 806-817.

[16] N.M. Jackson, M.I. Hammons. Use of Nondestructive Techniques to Estimate the Allowable Vibratory Compaction Level During Construction. Research Report FL/DOT/SMO/07-BDB-11, State Materials Office, March 2007.

[17] D.E. Siskind, M. Stagg. The Co-Report. Blast Vibration Damage Assessment Study and Report. Miami-Dade County, C3TS Project No.: 1322-01. 2000

[18] R. Hendriks. Transportation Related Earthborne Vibrations. California Department of Transportation Division of Environmental Analysis, Office of Noise, Air Quality, and Hazardous Waste Management Sacramento, CA, Technical Advisory, Vibration TAV-02-01-R9601, February 2002. 